\title{
EL CONTROL DE LA ACTIVIDAD JUDICIAL Y LAS TEORÍAS JURÍDICAS ACTUALES*
}

\author{
Rafael Hernández Marín*** \\ Universidad de Murcia \\ rafaber@um.es
}

RESUMEN. El pensamiento jurídico actual está dominado por teorías acerca de diferentes aspectos de la actividad judicial que no permiten controlar si los jueces cumplen o no las obligaciones que el Derecho les impone. Entre dichas teorías figuran teorías acerca de cuáles son las obligaciones de los jueces, teorías acerca de la motivación de las decisiones judiciales, teorías ontológicojurídicas acerca de la naturaleza del Derecho, teorías relacionadas con la aplicación del Derecho y teorías de la interpretación del Derecho.

Palabras clave: motivación de las decisiones judiciales, aplicación del Derecho.

\section{The Control of Judicial Activity and Current Legal Theories}

ABSTRACT. Current legal thinking is dominated by theories about different aspects of judicial activity that do not allow one to control whether judges comply with the obligations imposed upon them by the law. These theories include theories about the obligations of judges, theories about the motivation of judicial decisions, ontological-legal theories about the nature of law, theories related to the application of law and theories of interpretation of law.

Keywords: motivation of judicial decisions, application of law.

* Fecha de recepción: 11 de diciembre de 2016. Fecha de aceptación: 15 de marzo de 2017.

La investigación realizada en este trabajo se inscribe en el marco del proyecto de investigación DER201674898-C2-1-R, «Conflictos de derechos, tipologías, razonamientos, decisiones», financiado por el Ministerio de Economía y Competitividad del Gobierno de España, AEI y FEDER.

** Catedrático de Filosofía del Derecho, Universidad de Murcia. 


\section{INTRODUCCIÓN}

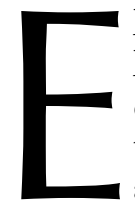

1 respeto a la legalidad es esencial en un Estado de Derecho. Y, para que la legalidad sea respetada, es necesario que los jueces cumplan las obligaciones que el Derecho les impone. Si los jueces no cumplieran sus obligaciones castigando a quienes delinquen, a quienes incumplen un contrato o causan daño a otro, la legalidad no sería respetada.

Por esta razón, es importante, desde el punto de vista teórico, saber si los jueces cumplen o no sus obligaciones. Es importante, podemos decir también, controlar a nivel teórico si en un caso determinado un juez determinado cumple o no las obligaciones que el Derecho le impone. Pero a este respecto tropezamos con la dificultad siguiente: el pensamiento jurídico actual está dominado por teorías acerca de diferentes aspectos de la actividad judicial que no permiten controlar si los jueces cumplen o no las obligaciones que el Derecho les impone. Dicho de otro modo, si esas teorías dominantes fueran verdaderas, sería imposible decir que un juez ha hecho algo mal en casos en los que parece evidente que el juez ha hecho algo mal.

Entre esas teorías relativas a diferentes aspectos de la actividad judicial figuran teorías acerca de cuáles son las obligaciones de los jueces, teorías acerca de la motivación de las decisiones judiciales, teorías ontológico-jurídicas acerca de la naturaleza del Derecho, teorías relacionadas con la aplicación del Derecho y teorías de la interpretación del Derecho.

\section{TEORÍAS ACERCA DE LAS OBLIGACIONES DE LOS JUECES}

El Derecho prevé que los jueces intervengan en asuntos diversos: procedimientos de jurisdicción voluntaria, juntas electorales, autorizaciones de registros domiciliarios o escuchas telefónicas, etc. Sin embargo, muchas de estas actuaciones podrían ser encomendadas por el Derecho a otros órganos o instancias. Lo que es consustancial a la condición de juez es su intervención en la resolución de un litigio o controversia entre dos partes que tiene lugar en un juzgado.

En un litigio dirimido en un juzgado, un juez está obligado por el Derecho a realizar esencialmente tres actividades: una actividad procesal, una actividad decisoria y una actividad justificatoria.

La actividad decisoria consiste en dictar una decisión que resuelva el litigio que ha llegado al juzgado. Es la actividad esencial del juez en un litigio. Pues la obligación fundamental de un juez es juzgar; y juzgar consiste precisamente en dictar una decisión que resuelva un litigio.

Esa decisión, según muchos ordenamientos jurídicos actuales, entre ellos el español, ha de ir acompañada de una motivación. De ahí que otras de las actividades que un juez realiza y está obligado por el Derecho a realizar en un litigio es una actividad justificatoria, justificatoria de la decisión que ha dictado para resolver el litigio, justificatoria de su actividad decisoria. 
Aunque, previamente a la actividad decisoria y a la actividad justificatoria, el juez ha de realizar una actividad procesal, integrada por diferentes actos procesales, que varían según cuál sea el tipo de proceso y el ordenamiento jurídico de que se trate. La actividad procesal del juez es estudiada por la dogmática-jurídica procesal y su análisis no es relevante para los temas de los que me voy a ocupar. Me referiré solo a la actividad decisoria y a la actividad justificatoria del juez.

Las ideas que acabo de exponer acerca de cuáles son las actividades de un juez en un litigio son pacíficas, según creo. Pero sí es discutida, aunque pueda parecer lo contrario, la siguiente observación relativa a la actividad decisoria del juez: la actividad decisoria realizada por un juez para resolver un litigio no puede consistir en dictar una decisión cualquiera. Ciertamente, dictando una decisión cualquiera, el juez cumple su obligación de juzgar. Pero el Derecho exige algo más a la actividad decisoria del juez. Exige que la decisión dictada por el juez para resolver un litigio cumpla ciertos requisitos.

No se trata de que esa decisión del juez haya de ser conforme a ciertas normas o principios morales o éticos, extra-jurídicos. Las teorías que plantean estas exigencias extra-jurídicas a las decisiones judiciales pueden ser incluidas entre esas teorías, a las que he aludido inicialmente, que no permiten controlar la actividad judicial, puesto que dichas exigencias diluyen las obligaciones que el Derecho impone a los jueces en normas o principios morales, de los cuales lo menos que se puede decir es que su contenido es impreciso.

Es el propio Derecho el que establece cómo han de ser las decisiones dictadas por los jueces para resolver los litigios. El Derecho impone ciertas exigencias a las decisiones que los jueces dicten al juzgar. De una decisión judicial que satisface o cumple esas exigencias puede decirse que es una decisión conforme al Derecho o jurídicamente correcta.

Por esta razón, sostengo que, al margen de las actividades u obligaciones procesales, el Derecho impone a los jueces tres obligaciones básicas, que son las siguientes: juzgar o decidir los litigios, decidirlos conforme al Derecho y motivar sus decisiones.

Más adelante me detendré en esa segunda obligación básica de los jueces, la de decidir los litigios conforme al Derecho. Lo que ahora deseo destacar es que, en la jurisprudencia y en obras doctrinales, esta segunda obligación de los jueces queda medio oculta bajo una capa de hojarasca terminológica, que impide visualizarla con nitidez. Allí se atribuye a los jueces la obligación de dictar decisiones basadas en el Derecho, o justificadas según el Derecho, o de justificar (basar) sus decisiones en el Derecho, o de fundamentar o motivar en el Derecho sus decisiones, etc. Es difícil saber si estas diversas locuciones, no necesariamente equivalentes entre sí, se refieren a la obligación de dictar decisiones que sean conformes al Derecho o a la obligación de motivar las decisiones judiciales o bien a una obligación híbrida entre esas dos obligaciones. En cualquier caso, el Derecho no impone a los jueces tal obligación híbrida.

Esa falta de claridad terminológica respecto a lo que yo considero que es la segunda de las obligaciones básicas de los jueces, la obligación de decidir los litigios conforme al Derecho, refleja la situación del pensamiento jurídico actual respecto a la actividad judicial. Pues tanto los procesalistas, como los constitucionalistas, así como los filósofos del Derecho, que desde hace varias décadas vienen estudiando la actividad 
judicial, e incluso los jueces cuando analizan su propia actividad, saltan de la obligación de decidir los litigios a la obligación de motivar las decisiones, pasando por alto la obligación de que las decisiones dictadas sean conformes al Derecho.

Este olvido lo observamos en C. E. AlChOURRÓn, cuando este afirma que son «principios» de una «sociedad contemporánea» los tres siguientes: $\left.1 .^{\circ}\right)$ los jueces deben decidir los casos que son sometidos a su consideración («principio de inexcusabilidad», lo llama AlCHOURRÓN; yo lo llamaría «obligación de juzgar»); $2 .^{\circ}$ ) las decisiones judiciales deben ser fundadas (principio de justificación, según ALCHOURRÓN), y $3 .^{\circ}$ ) el fundamento de las decisiones judiciales han de ser normas jurídicas (principio de legalidad, según el propio ALCHOURRÓN $)^{1}$. ALCHOURRÓN no menciona, ni como obligación de los jueces ni como principio, el decidir los casos litigiosos conforme al Derecho. Pero es esto, el decidir los casos litigiosos conforme al Derecho, y no el fundamentar las decisiones en el Derecho, lo que exige, dicho en términos convencionales, el principio de legalidad.

El mismo olvido se observa en R. ALEXY, cuando este dice que «el análisis de las decisiones jurídicas es el análisis de las fundamentaciones» ${ }^{2}$. Según esta tesis, el único aspecto importante de una decisión judicial es su motivación. Y, si se acepta esta idea, es comprensible que se afirme que la corrección de una decisión judicial depende de su motivación. Esto es lo que hace A. NIETO, al escribir que el fallo, o sea, la decisión judicial que resuelve un litigio, no es por sí mismo correcto o incorrecto. Estos calificativos solo se aplican a la argumentación, o sea, a la motivación. Una decisión judicial será correcta o incorrecta, dice NIETO, en la medida en que lo sean sus argumentos de apoyo ${ }^{3}$.

Yo no comparto las tesis que acabo de exponer, que hacen depender la corrección de una decisión judicial de la corrección de su motivación. Pienso que una decisión judicial correcta es una decisión judicial jurídicamente correcta, o sea, conforme al Derecho. Pero lo peor de esas tesis son, en mi opinión, las consecuencias que resultan cuando dichas tesis se unen a las teorías dominantes acerca de la motivación de las decisiones judiciales. Voy a exponer y comentar a continuación estas teorías.

\section{TEORÍAS DE LA MOTIVACIÓN DE LAS DECISIONES JUDICIALES}

\subsection{Concepciones de la motivación de las decisiones judiciales}

Según opinión doctrinal mayoritaria, la motivación de una decisión judicial consiste en un razonamiento justificatorio de la decisión o en una justificación racional de la decisión.

Ciertamente, en la actualidad todas o casi todas las sentencias judiciales contienen razonamientos justificatorios de las decisiones contenidas en sus fallos respectivos, ya sean razonamientos en sentido estricto, ya sean, como es lo más frecuente, conjuntos o cadenas de razonamientos. Pero sostener que toda justificación racional de una deci-

\footnotetext{
1 AlChOURRÓN, 1996: 333.

2 AleXy, 2003: 10.

3 Nieto, 2000: 273-274.
} 
sión judicial constituye una motivación tropieza con las dificultades que voy a exponer a continuación.

Supongamos que Carmen ha matado a alguien, es acusada ante un juez de homicidio y no existe duda acerca de su culpabilidad, ni concurren circunstancias eximentes, etc. Y supongamos también que el juez dicta una decisión condenatoria, que castiga a Carmen a una pena de doce años de prisión, y justifica esta decisión con el razonamiento siguiente:

[1] Los homicidas deben ser castigados con una pena de prisión de diez a quince años [primera premisa] ${ }^{4}$; Carmen es una homicida [segunda premisa]. Por tanto, Carmen debe ser castigada a doce años de prisión [conclusión].

Este razonamiento [1] es un razonamiento justificatorio de la decisión condenatoria que constituye su conclusión o una justificación racional de esa decisión. Y parece que no se puede dudar de que ese razonamiento sea una motivación de dicha decisión condenatoria. Sin embargo, la realidad es que sí pueden existir dudas al respecto. Estas dudas surgen cuando nos imaginamos la posibilidad de que, en ese mismo supuesto de la homicida Carmen, el juez hubiera dictado una decisión absolutoria y hubiera justificado su decisión alegando que Carmen tiene dos hijos de corta edad, que dependen económicamente de la madre, quien siempre ha cuidado de sus hijos, los cuales estarán mejor atendidos por la madre que por los servicios sociales y que existen numerosos preceptos jurídicos que exigen proteger a los menores de edad por encima de todo (cabría invocar el «principio del interés superior del menor»). Es decir, supongamos que, en el caso citado, el juez dicta una decisión absolutoria y justifica esta decisión mediante el razonamiento siguiente:

[2] Los menores deben ser protegidos [primera premisa]; los hijos de Carmen estarán mejor atendidos por su madre que por los servicios sociales [segunda premisa]. Por tanto, Carmen debe ser absuelta [conclusión].

Qué duda cabe de que también este segundo razonamiento es un razonamiento justificatorio de la decisión absolutoria que constituye su conclusión. Y si la motivación de una decisión judicial consiste solamente en eso, en un razonamiento justificatorio de la decisión, es innegable que también este razonamiento [2] es una motivación de la decisión absolutoria que constituye su conclusión. No es posible, pues, distinguir a este respecto entre los razonamientos [1] y [2].

Incluso si se precisara, como a veces se hace, que la motivación de una decisión judicial es un razonamiento justificatorio de la decisión, que consiste en dar las razones fácticas y jurídicas del por qué de una decisión ${ }^{5}$, también habría que decir que el razonamiento [2] es una motivación. Pues, al formular este razonamiento, el juez ha dado las razones fácticas («Los menores estarán mejor atendidos por la madre que por los servicios sociales») y jurídicas («Los menores deben ser protegidos») de su decisión absolutoria.

La cuestión que estoy ahora planteando, la de si esos dos razonamientos constituyen motivaciones, no puede ser solventada diciendo que, en el segundo ejemplo, la

\footnotetext{
4 Esta es la pena prevista para el homicidio en el Código Penal español (art. 138).

5 Cabría invocar a este respecto el inicio del art. 218.2 de la LEC («Las sentencias se motivarán expresando los razonamientos fácticos y jurídicos»).
} 
decisión absolutoria no es correcta y, por ello, ese segundo razonamiento no es una motivación. Pues si se piensa, como yo opino, que la corrección de una decisión judicial y su justificación o motivación son recíprocamente independientes, el que esa decisión sea incorrecta no implica que la justificación que la acompaña no sea una motivación. Y si se piensa, como las teorías de las que acabo de hablar, que la corrección de una decisión judicial depende de la corrección de su motivación, y aceptamos que la motivación de una decisión judicial consiste en una justificación racional de la decisión, la consecuencia sería la siguiente: el razonamiento [2], al ser una justificación racional de la decisión absolutoria que constituye su conclusión, es una motivación, o incluso una motivación correcta, de dicha decisión; y, al ser correcta esta motivación, la decisión que constituye su conclusión también es correcta.

Tampoco es posible evitar la conclusión de que el razonamiento [2] es una motivación de la decisión absolutoria que constituye su conclusión partiendo de lo que los altos Tribunales españoles entienden por «motivación».

Por ejemplo, el Tribunal Constitucional, en su Sentencia 123/1997, de 1 de julio, FJ $3 .^{\circ}$, dice que la motivación consiste en «una exteriorización del razonamiento que conduce desde los hechos probados y las correspondientes consideraciones jurídicas al fallo». Si la motivación de una decisión judicial consiste en esto, el razonamiento [2] es una motivación indudablemente. Lo mismo se puede decir si partimos de la concepción de la motivación expresada en la STC 212/2014, de 18 de diciembre, en cuyo FJ $3 .^{\circ}$ se afirma que una sentencia judicial está motivada cuando contiene «los elementos y razones de juicio que permitan conocer cuáles han sido los criterios jurídicos que fundamentan la decisión». Y tampoco la STS, de la Sala de lo Civil, 233/2013, de 25 de marzo, permite evitar la conclusión de que el razonamiento [2] constituye una motivación; pues en su FJ 4. ${ }^{\circ}$ se lee lo siguiente: «El deber de motivación de la sentencia se resume en la exigencia de una respuesta judicial fundada en Derecho, que se anude con los extremos sometidos por las partes a debate».

A mi juicio, ninguna de las concepciones o caracterizaciones examinadas acerca de lo que es la motivación de una decisión judicial resulta satisfactoria. Esencialmente porque son tan poco exigentes, incluso con frecuencia tan imprecisas, que cualquiera de ellas permite considerar como motivación de una decisión judicial casi cualquier razonamiento justificatorio de una decisión, como el razonamiento [2]. Y cuando a estas concepciones de la motivación de las decisiones judiciales se les añade la tesis de ALEXY, antes citada, conforme a la cual el análisis de las decisiones judiciales se reduce al análisis de sus motivaciones, o sea, la tesis de que lo único importante de una decisión judicial que resuelve un litigio es la motivación que la acompaña, la consecuencia es la siguiente: si la justificación de una decisión judicial dictada en un caso determinado no contiene ningún disparate, el juez habrá cumplido en ese caso todas las obligaciones que el Derecho le impone. Una consecuencia, a mi juicio, devastadora, pues anula cualquier posibilidad de controlar la actividad judicial. Por ejemplo, conforme a dichas tesis, en ese caso de la homicida Carmen del que antes hablaba, el juez que dicta una decisión absolutoria y la justifica mediante el razonamiento [2] habría cumplido todas sus obligaciones.

Mi concepción de la motivación de las decisiones judiciales parte de las reflexiones siguientes. Consideremos los razonamientos «Ayer no fui a trabajar, porque estuve 
enfermo» $\mathrm{y}$ «Date prisa, porque es tarde». De ellos cabría decir que son razonamientos justificatorios de sus conclusiones o justifican racionalmente sus conclusiones («Ayer no fui a trabajar» $\mathrm{y}$ «Date prisa», respectivamente), pero no intentan probar cosa alguna. En cambio, el razonamiento «Pienso, luego existo» y el razonamiento «Todos los hombres son mortales; Sócrates es hombre. Por tanto, Sócrates es mortal» son razonamientos justificatorios de sus respectivas conclusiones en el sentido preciso de que intentan probar que sus conclusiones respectivas son verdaderas.

Nuestros razonamientos de la vida diaria son de los dos tipos. Pero los razonamientos técnicos o científicos solo son del segundo tipo. Y creo que también la motivación de una decisión judicial tendría que ser un razonamiento de este tipo, un razonamiento que pretende probar algo. Concretamente, y dado que el Derecho obliga a los jueces a dictar decisiones que sean conformes al Derecho, la motivación de una decisión judicial es, o al menos debería ser, un razonamiento que intentara probar que la decisión es conforme al Derecho.

Si la motivación de una decisión judicial es entendida de este modo, resulta evidente la relación que existe entre la segunda de las obligaciones básicas de los jueces, la de decidir conforme al Derecho, y la tercera de esas obligaciones, la de motivar las decisiones. Pues dicha relación no consiste en que el Derecho imponga a los jueces una obligación híbrida entre ellas: la obligación de dictar decisiones basadas o justificadas en Derecho, o justificables según el Derecho, o de motivar las decisiones en Derecho, etc. Consiste en que la tercera de esas obligaciones, la obligación de motivar, es un intento de probar el cumplimiento de la segunda, un intento de probar que la decisión dictada es conforme al Derecho.

La conclusión final de un razonamiento que pretende probar que una decisión judicial es conforme al Derecho ha de ser un enunciado asertivo, o sea, un enunciado verdadero o falso, que afirma que la decisión es conforme al Derecho (del mismo modo que la conclusión final de un razonamiento que pretende probar que hay agua en Marte, o del que pretende probar que Dios existe, solo puede ser un enunciado asertivo que afirma que hay agua en Marte, o que Dios existe, respectivamente). Pero esto no ocurre en los razonamientos [1] y [2]. Ninguno de estos dos razonamientos tiene como conclusión un enunciado asertivo, que afirma que una decisión determinada es conforme al Derecho. Por ello, dichos razonamientos no pretenden probar que una determinada decisión es conforme al Derecho y no son, por tanto, motivaciones, en mi opinión, aunque sean considerados así usualmente.

En resumen, la teoría de la motivación que sostengo, que evita considerar el razonamiento [2] como una motivación, tiene también como consecuencia que tampoco el razonamiento [1] sea una motivación.

\subsection{Razonamientos integrantes de la motivación de una decisión judicial}

Otro aspecto de la motivación de las decisiones judiciales que ha suscitado multitud de teorías que dificultan el control de la actividad judicial es el de los razonamientos integrantes de la motivación. 
Este asunto ha dado lugar en las tres o cuatro últimas décadas a una temática conocida como «argumentación jurídica», «razonamiento jurídico», etc. Los términos «argumentación», «argumento», «razonamiento», «inferencia», etc., significan todos lo mismo: secuencia de enunciados, formulados con la pretensión o creencia de que uno de los enunciados de la secuencia, denominado «conclusión», es apoyado por los restantes, denominados «premisas». Pero el adjetivo «jurídico(a)» acompañando al sustantivo «razonamiento» o «argumentación» siempre me ha causado perplejidad. Los trabajos dedicados a este tema raramente afrontan directamente la cuestión de en qué se diferencian los razonamientos jurídicos de los razonamientos no jurídicos. Y los que sí se plantean este problema no lo resuelven satisfactoriamente.

Por ejemplo, en el capítulo introductorio de SCHAUER, 2013, titulado «¿Existe el razonamiento jurídico?», el autor anuncia que el objetivo de esa obra es distinguir los razonamientos jurídicos de los no jurídicos. Sin embargo, en las escasas ocasiones en las que el autor usa las palabras «premisa» o «conclusión» a lo largo del libro, nunca es para distinguir los razonamientos jurídicos de los no jurídicos, a pesar de que lo que distingue a un razonamiento de otro, o a una forma de razonamiento de otra, solo puede ser alguna diferencia relacionada con sus respectivas premisas o conclusiones. Tengo la impresión de que la mayoría de los juristas piensan que los razonamientos jurídicos son razonamientos integrado por enunciados (premisas y conclusiones) que se refieren a algún asunto jurídico ${ }^{6}$. Pero esto es como decir que los razonamientos utilizados para desvelar la composición de una sustancia son razonamientos químicos o los de un oculista, oftalmológicos.

La confusión aumenta cuando, sin haber aclarado previamente qué es un razonamiento jurídico, los autores disputan acerca de si el razonamiento jurídico es o no una especie de razonamiento moral o de razonamiento práctico, también sin haber aclarado previamente qué es un razonamiento moral o un razonamiento práctico. Mas, cualquiera que sea el sentido y solución de estas disputas, me parece que esos razonamientos jurídicos, morales, prácticos, etc., de los que se habla no son razonamientos ordinarios, es decir, razonamientos integrados exclusivamente por enunciados asertivos. No son razonamientos como «Pienso, luego existo» y «Todos los hombres son mortales; Sócrates es hombre. Por tanto, Sócrates es mortal». En cualquier caso, lo que sí parece claro es que, según las ideas dominantes en el pensamiento jurídico actual, la motivación de una decisión judicial está integrada, al menos parcialmente, por razonamientos no ordinarios.

Ello tiene la consecuencia siguiente. En el caso de los razonamientos ordinarios existen criterios, de los que voy a hablar enseguida, para decidir si un determinado razonamiento ordinario es o no válido o correcto. Pero esos criterios no existen tratándose de razonamientos no ordinarios. Respecto a los razonamientos integrados exclusivamente por enunciados prescriptivos, en casi setenta años la lógica de normas no ha

6 Así entiende los razonamientos jurídicos HernÁNDEZ GIL, 1975: 61, en el siguiente pasaje, en el que aborda expresamente el problema de la distinción entre razonamientos jurídicos y razonamientos no jurídicos: «El razonamiento jurídico es una variante del razonamiento en general y el razonamiento del abogado una modalidad o especie y, en algún sentido, una fase del razonamiento jurídico. En ambos supuestos (el del razonamiento jurídico respecto del general o de otros tipos de razonamiento y el peculiar del abogado respecto del jurídico) la variación especificativa viene determinada principalmente por la materia y la función». 
conseguido consolidar un criterio que permita determinar si esos razonamientos son o no válidos o correctos. $\mathrm{Y}$, en cuanto a los razonamientos mixtos, como el denominado «silogismo judicial», prototipo de razonamiento jurídico, o los razonamientos [1] y [2], en los que figuran enunciados asertivos y enunciados prescriptivos, ni siquiera existen intentos de hallar tales criterios ${ }^{7}$. Por ello, si un juez, en la motivación de una decisión, usa o formula uno de estos razonamientos no ordinarios carecemos de criterios, al menos a primera vista, para saber si el juez está haciendo bien o mal su trabajo, no tenemos criterios para controlar ese aspecto de la actividad judicial.

No existen tales criterios, acabo de decir, a primera vista. Pues sí existe, al menos en la legislación española, un criterio legal, que permite pronunciarse sobre todos los razonamientos integrantes de la motivación de una decisión judicial. Es el art. 218.2 de la Ley de Enjuiciamiento Civil («LEC», en adelante), que exige que los razonamientos integrantes de la motivación se ajusten siempre a las reglas de la lógica y la razón.

Las reglas de la lógica (como la regla modus ponendo ponens, la regla de eliminación de la conjunción o la de introducción del cuantificador existencial) son formas de razonamiento válidas deductivamente. Y las reglas de la razón son ante todo las reglas de la razón científica, que exigen decir o al menos buscar la verdad. Por ello, entiendo que el artículo de la LEC que acabo de citar exige que todos los razonamientos integrantes de la motivación de una decisión judicial sean, como los razonamientos científicos, razonamientos ordinarios válidos deductivamente o al menos inductivamente; es decir, exige que todos los razonamientos integrantes de la motivación de una decisión judicial sean razonamientos tales que sea imposible, o al menos improbable, que sus premisas sean verdaderas y su conclusión, falsa.

Pero, aparentemente, los altos Tribunales españoles no saben qué son las reglas de la lógica. La STC 135/2003, de 30 de junio, en su FJ 3..$^{\circ}$, razona de la manera siguiente: «resulta conforme a las reglas de la lógica concluir, a partir de la presencia de las huellas dactilares del recurrente en el lugar de los hechos, su participación en los mismos». Este razonamiento es válido, válido inductivamente. Pues siendo verdadera su premisa («Hay huellas dactilares del recurrente en el lugar de los hechos»), es muy probable que también lo sea su conclusión («El recurrente participó en los hechos»). Pero el razonamiento no es válido deductivamente, puesto que, aunque su premisa sea verdadera, su conclusión podría ser falsa. Y dado que las reglas de la lógica son formas de razonamiento válidas deductivamente, el razonamiento citado no es conforme a las reglas de la lógica. Mayor desconocimiento de lo que son estas reglas se aprecia en la STS, de la Sala de lo Civil, 888/2010, de 30 de diciembre, en cuyo FJ 2. ${ }^{\circ}$ aparece el pasaje siguiente, repetido en numerosas sentencias posteriores de la misma Sala: «La lógica a que se refiere el art. 218.2 LEC es la de la argumentación —entramado argumentativo-, exposición de razones o consideraciones en orden a justificar la decisión». Pues lo que viene a decir el Tribunal Supremo en este pasaje es que cualquier

7 La única excepción que conozco es un artículo reciente: VRANAS, 2016. En este trabajo, el autor presenta una definición de validez de los razonamientos, cualquiera que sea el tipo de discurso, asertivo o prescriptivo, de las premisas y la conclusión del razonamiento. Sin embargo, los puntos de partida de este trabajo son muy discutibles, y mucho más lo son sus conclusiones. Me limitaré a citar una de ellas. Según VRANAS, un ejemplo de razonamiento mixto válido es el siguiente, que cito textualmente: «Marry me. So: Possibly, there is a reason for you to marry me». 
argumento o razonamiento tendente a justificar una decisión judicial es conforme a las reglas de la lógica. Una tesis que, si fuera verdadera, enervaría la obligación de motivar que el Derecho impone a los jueces.

Mas, al margen de cuáles sean las opiniones de los altos Tribunales españoles acerca de las reglas de la lógica y de la razón, lo cierto es que los razonamientos [1] y [2] no respetan dichas reglas, dado que no son válidos, ni deductiva, ni inductivamente ${ }^{8}$. Por ello, infringen el precepto procesal comentado. De manera que, si dichos razonamientos fueran motivaciones, serían motivaciones ilegales.

\section{TEORÍAS ONTOLÓGICO-JURÍDICAS}

La segunda de las obligaciones básicas de los jueces es dictar decisiones que sean conformes al Derecho. Y esta observación nos conduce inevitablemente a la cuestión más antigua y difícil de la filosofía jurídica: el problema de la naturaleza del Derecho.

En mi opinión, el Derecho de un país está integrado solo por los enunciados, esto es, expresiones bien formadas y con sentido completo, que aparecen en cuerpos jurídicos, o sea, en leyes, en decretos, en la constitución, etc. Pero no es esta la opinión dominante en el pensamiento jurídico. Para exponer algunas de las teorías ontológico-jurídicas actuales y sus consecuencias, es útil comentar la STS 76/2015, de 17 de febrero.

En esta sentencia, se afirma que en «términos de estricta legalidad vigente no existe duda respecto de la decisión adoptada por la sentencia recurrida, conforme a lo dispuesto en el artículo 109 del Código Civil, artículo 53 y siguientes de la Ley de Registro Civil». No obstante, y a pesar de que la sentencia recurrida en ese procedimiento de casación se ajustaba estrictamente a la legalidad, según opinaba el propio Tribunal Supremo, este casó la sentencia «en aplicación del principio del interés superior del menor», diciéndolo brevemente; un principio que, según dicho Tribunal, «late» en toda la normativa internacional, nacional y autonómica. Mediante esta metáfora, el Tribunal Supremo expresa la tesis ontológico-jurídica de que existe un principio jurídico determinado. Pero esta tesis, por sí sola, no basta para comprender el proceder del Tribunal Supremo en esta sentencia. Pues, aceptada la existencia de tal principio, cabe preguntarse por qué el Tribunal Supremo considera evidente, tan evidente que no necesita ninguna justificación, que el elemento del Derecho que ha de ser aplicado en el litigio en cuestión es dicho principio, y no esos enunciados contenidos en el Código Civil y en la Ley de Registro Civil, que también son elementos del Derecho, y que el propio Tribunal cita en su sentencia. Cabría añadir que el Tribunal considera que los principios son superiores a las leyes. Pero esta tesis complementaria, que afirma la existencia de una determinada relación jerárquica entre los principios y las leyes, además

8 Conviene advertir respecto al razonamiento ([1] respecto al razonamiento [2], una observación similar sería ociosa), que ni siquiera sería válida ni deductiva, ni inductivamente, el razonamiento resultante de sustituir en [1] los enunciados prescriptivos que figuran en él, los enunciados «Los homicidas deben ser castigados con una pena de prisión de diez a quince años» y «Carmen debe ser castigada a doce años de prisión», por sus correspondientes enunciados asertivos (o sea, por los enunciados «Los homicidas son castigados con una pena de prisión de diez a quince años» $\mathrm{y}$ «Carmen es castigada a doce años de prisión», respectivamente). 
de gratuita, es insuficiente para entender el comportamiento del Tribunal Supremo en dicha sentencia.

Se trata de una tesis gratuita, es decir, carente de justificación, al menos en la más elaborada de las concepciones jerárquicas del Derecho, que es la de H. Kelsen. Pues KELSEN sostiene una concepción normativista del Derecho, en la que los principios no tienen sitio.

Por otra parte, aunque la afirmación «Los principios son superiores a las leyes» fuera verdadera, dicha afirmación no implica la prescripción «Los jueces han de aplicar los principios antes que las leyes»; del mismo modo que, aunque aceptemos la tesis de que las leyes son superiores a los reglamentos, esta tesis no implica la prescripción «Los jueces han de aplicar las leyes antes que los reglamentos». Si aceptamos este último enunciado, es porque lo entendemos, no como una prescripción, sino como una aserción que afirma que existe un elemento del Derecho, concretamente, un enunciado jurídico (contenido en el art. 6 de la Ley Orgánica del Poder Judicial), según el cual los jueces han de aplicar las leyes antes que los reglamentos. Por todo ello, para entender el proceder del Tribunal Supremo en esa sentencia, hay que suponer que dicho Tribunal admite la existencia de un elemento del Derecho, que no puede ser otra cosa que un principio, un principio muy particular, llamémosle «P», que exige a los jueces aplicar los principios antes que las leyes. Pero los principios en general y este principio $P$ en particular, además de ignorar lo que nos enseñaron la vida y obras de PlATÓN, crean numerosos problemas prácticos y teóricos.

Uno de esos problemas prácticos consiste en que ese principio $P$, que exige aplicar los principios antes que las leyes, sustituye el imperio de la ley por la tiranía, e incluso el despotismo, de los principios (y uso estos términos en el sentido estricto de un poder que ha sido usurpado al gobierno legítimo de las leyes, y es ejercido sin sujeción a leyes, ni control) ${ }^{9}$. Por otro lado, si esas teorías ontológico-jurídicas que admiten la existencia de principios jurídicos fueran verdaderas, algunos aspectos esenciales de la actividad judicial serían incontrolables. Pues no solo en el caso resuelto en la sentencia del Tribunal Supremo que acabo de comentar, sino también en otros muchos casos no es difícil invocar algún principio que exija algo opuesto a lo que exige claramente un enunciado jurídico. Por lo cual sería muy difícil, en todos estos casos, saber qué es lo que el Derecho exige a un juez y si su decisión es conforme al Derecho.

En cuanto a los problemas teóricos que suscitan los principios en general y ese principio $P$ en particular, son numerosos.

El fundamental de todos ellos, aunque lo dejaré a un lado, es el de la naturaleza de esos principios, de qué están hechos, puesto que solo pueden ser entidades ideales.

Una segunda cuestión, epistemológica, es la de cómo se conoce su existencia y cómo se determina su contenido, o sea, cómo saber qué es lo que exigen los principios. Los magistrados de los altos Tribunales, en especial, de los Tribunales constitucionales, parecen tener a este respecto un don especial; como el que exhibían

9 «Llamo tirano al usurpador de la autoridad real, y déspota al usurpador del poder soberano. Un tirano es aquel que se pone contra las leyes a gobernar según ellas; un déspota, el que se hace superior a las mismas leyes. Así es que un tirano puede no ser déspota, pero todo déspota siempre es tirano» (RoUSSEAU, 1979: 479). 
aquellos juristas decimonónicos, que captaban las esencias de los conceptos jurídicos, siguiendo el método elaborado, y años más tarde ridiculizado, por R. v. IHERING. La seguridad con la que dichos magistrados saben cuáles son las exigencias de un principio jurídico determinado, la rotundidad de sus afirmaciones acerca del contenido de los derechos fundamentales, y su clarividencia al contemplar los valores constitucionales son pasmosas. Pues todos esos entes jurídicos constitucionales (principios, derechos, valores) tienen limitaciones en preceptos legales o reglamentarios, que son por esta razón inconstitucionales, aunque no son impugnados por nadie ${ }^{10}$; por ello, no es fácil saber qué es lo que dichos entes reclaman. De ahí los inevitables titubeos con los que afrontan estos temas juristas especializados en las ramas del Derecho correspondientes, en contraste con la determinación con la que los altos Tribunales se pronuncian respecto a esas cuestiones. Tampoco tienen dudas los altos Tribunales acerca de lo que es «razonable» en casos en los que los enunciados jurídicos dejan a los Tribunales un ámbito de discrecionalidad; en cambio, y también en contraste con ello, un especialista en una rama cualquiera del Derecho difícilmente pontificaría acerca de cuál es la decisión razonable en casos semejantes. Llama asimismo la atención la posición de los altos Tribunales cuando diferentes entes jurídicos constitucionales (principios, derechos, valores) confluyen en un mismo litigio. Pues si estos entes empujan en el mismo sentido, los altos Tribunales dejan traslucir su satisfacción. Pero, si presionan en sentidos opuestos, dichos Tribunales se sienten obligados a imponer a esos entes un orden, una jerarquía; cosa que, al mismísimo KELSEN, el mayor teórico de la jerarquía normativa, le sería difícil admitir, dado que él pensaba que todo lo que forma parte de una constitución se halla al mismo nivel. Aunque lo que KELSEN sería absolutamente incapaz de entender, pues desborda sus esquemas mentales, es el hecho de que esas relaciones jerárquicas entre diferentes entes constitucionales pueden experimentar variaciones, bien de modo ocasional, en atención a un caso concreto, bien con cierta vocación de permanencia, debido a un cambio de jurisprudencia. KELSEN sería incapaz de asimilar la idea de una jerarquía «móvil», como a veces se dice.

Precisamente a propósito de esas relaciones jerárquicas, los principios en general y en particular ese principio $P$, que exige aplicar los principios antes que las leyes, plantean otro problema teórico, que es el siguiente: ¿qué nivel jerárquico ocupan dichos principios, en particular el principio $P$, en esa jerarquía de niveles, en la que los enunciados jurídicos constitucionales ocupan un nivel superior al de los enunciados contenidos en las leyes, estos un nivel superior al de los enunciados contenidos en decretos del gobierno, etc.?; los principios en general y el principio $P$ en particular $¿$ son superiores a las leyes?; ¿tienen el mismo rango que la Constitución o son superiores a la Constitución?; ¿es superior el principio $P$ a todos los demás principios?; ¿cuál es el criterio para decidir en general, dados dos elementos cualesquiera del Derecho (enunciados, principios, etc.), cuál de ellos es superior al otro?

10 Por ejemplo, contra el art. 19 de la Constitución, que proclama, sin ninguna limitación, el derecho de los españoles «a circular por el territorio nacional», chocan leyes y reglamentos estatales, así como ordenanzas y actos administrativos municipales, que regulan el tránsito de vehículos y la seguridad vial. Sin embargo, la colisión entre dicho precepto constitucional y, por ejemplo, la norma que ordena detenerse ante un semáforo en rojo no ha sido hasta ahora, que yo sepa, motivo de recurso o cuestión de inconstitucionalidad. 
Un último problema teórico que plantean los principios tiene que ver con la temática del Derecho y el tiempo. Si el Derecho está integrado solo por los enunciados que componen los cuerpos jurídicos, como yo opino, la cuestión de en qué fecha un enunciado que forma parte de un cuerpo jurídico se incorpora al Derecho y en qué fecha deja de pertenecer a él tiene una respuesta inicial simple: un enunciado integrante de un cuerpo jurídico se incorpora al Derecho en la fecha de su publicación y deja de pertenecer a él en la fecha de su derogación o anulación (aunque determinar cuál es la fecha de derogación o de anulación de un enunciado jurídico no es un problema sencillo). Pero si se piensa que el Derecho está integrado también por principios, es imposible saber en qué fecha se incorpora al Derecho o deja de pertenecer a él un principio, dado que los principios no tienen una fecha de publicación, ni tampoco de derogación o anulación, puesto que no son publicados, ni derogados o anulados.

\section{LA CONFORMIDAD DE LAS DECISIONES JUDICIALES AL DERECHO}

Vuelvo a repetir la tesis de que la segunda de las obligaciones básicas de los jueces es dictar decisiones que sean conformes al Derecho. En el pensamiento jurídico existen discrepancias, no solo respecto a qué es el Derecho, sino también respecto a qué es una decisión judicial conforme al Derecho.

En mi opinión, las exigencias que el Derecho impone a las decisiones judiciales son de dos clases: procesales, referentes al proceso seguido por el litigio al que la decisión pone fin, y materiales, referentes al contenido de la decisión. El cumplimiento de las primeras determina el que una decisión judicial sea procesalmente conforme al Derecho; mientras que, si cumple las segundas, la decisión será materialmente conforme al Derecho. En resumen, la conformidad de una decisión judicial al Derecho tiene dos aspectos: conformidad procesal y conformidad material.

Creo que esta noción de conformidad al Derecho es pacífica. Lo más polémico es sin duda determinar qué es una decisión judicial materialmente conforme al Derecho. Como primera aproximación, se puede decir que una decisión judicial materialmente conforme al Derecho es una decisión que tiene el contenido que según el Derecho debe tener, una decisión que tiene el contenido que el Derecho exige a las decisiones judiciales. Y lo que el Derecho exige al contenido de las decisiones judiciales es que estas, ya sean estimatorias, ya sean desestimatorias, digan el Derecho. Esta exigencia está contenida en el art. 117.3 y 117.4 de la Constitución y el art. 2 de la Ley Orgánica del Poder Judicial, que establecen que la única función de los jueces y Tribunales es la función jurisdiccional, o sea, la función de decir el Derecho, al juzgar y ejecutar lo juzgado.

Aunque es preciso observar que, según una opinión muy extendida, lo que los artículos que acaban de ser citados establecen es la identificación de la actividad jurisdiccional con la actividad de juzgar. Una identificación que tiene como consecuencia inmediata la reducción de las obligaciones básicas de los jueces a dos: juzgar o decidir litigios y motivar sus decisiones; y, como consecuencia más remota, el hacer depender la corrección de una decisión judicial de su motivación, como en las teorías comentadas en páginas anteriores. 
Simplificando la cuestión, lo que significa dejar un lado alguna matización importante, se puede decir que una decisión judicial que dicte el Derecho es una decisión que aplica el Derecho.

A mi juicio, y también ahora dejo a un lado alguna opinión discrepante, aplicar el Derecho es aplicar un elemento del Derecho (no todos los elementos del Derecho). Y si los elementos del Derechos son, como yo opino, los enunciados integrantes de los cuerpos jurídicos, aplicar el Derecho es aplicar uno de estos enunciados; aplicar el Derecho es aplicar un enunciado jurídico.

Pero esta tesis tropieza con una dificultad, que tiene que ver con el tema central de este trabajo. Son muchos los autores que consideran que las normas o enunciados generales que los jueces formulan a veces en sus sentencias son normas jurídicas o enunciados jurídicos; y, por ello, sostienen que los jueces crean Derecho. Esta es una tesis aceptable. Lo cuestionable es si los jueces pueden o deben crear Derecho. Más adelante me referiré a esta cuestión. Lo que ahora deseo destacar es que si consideramos que los enunciados generales que los jueces formulan a veces en sus sentencias son enunciados jurídicos y decimos que aplicar el Derecho es aplicar un enunciado jurídico, la consecuencia es la siguiente: aplica el Derecho una decisión judicial $D$ que aplica un enunciado general $E$ formulado por el juez en la misma sentencia que contiene esa decisión $D$. Y podría ocurrir que $D$ fuera una decisión que estimara una petición $P$ absurda o carente hasta entonces de cualquier fundamento jurídico; y que el enunciado general $E$ formulado por el juez fuera un enunciado nuevo, creado ad hoc por el juez para prestar fundamento a esa petición $P$, y para presentar la decisión $D$, estimatoria de $P$ y que aplica el nuevo enunciado $E$, como una decisión que aplica el Derecho. El resultado de ello sería que no existiría ningún criterio, independiente del propio juez que dicta esa decisión $D$, para controlar si $D$ aplica el Derecho; y además la aplicación del Derecho se convertiría en una trivialidad.

Para evitar estas consecuencias, caben dos opciones. Una es negar que los jueces creen Derecho, o sea, sostener que los enunciados generales formulados por los jueces en sus sentencias no son jurídicos. Esta opción implica que una decisión judicial que aplica un enunciado creado por los jueces no aplica un enunciado jurídico y, por tanto, no aplica el Derecho. La otra opción es aceptar que los enunciados generales creados por los jueces son enunciados jurídicos y, por tanto, que una decisión judicial que aplica uno de estos enunciados aplica un enunciado jurídico. Pero entonces habría que corregir la noción de aplicación del Derecho y exigir, como condición necesaria para que una decisión judicial aplique el Derecho, que el enunciado jurídico aplicado por la decisión sea anterior a la decisión ${ }^{11}$.

\section{LA APLICACIÓN DE LOS ENUNCIADOS JURÍDICOS}

La tesis de que aplicar el Derecho es aplicar un enunciado jurídico ha de ser matizada de alguna de las maneras que acaban de ser sugeridas, a fin de que sea posible

${ }^{11}$ En sentido parecido se pronuncia GUASTINI, 1996: 380: «Las decisiones judiciales han de ser extraídas de reglas jurídicas preexistentes». 
controlar si una decisión judicial determinada aplica el Derecho, o sea, para controlar si una decisión judicial es materialmente conforme al Derecho, y, en definitiva, si un juez determinado cumple la segunda de sus obligaciones básicas.

Pero la posibilidad de realizar ese control depende también de las teorías que se sostengan en temas relacionados con la aplicación de los enunciados jurídicos. Y a este respecto cabe señalar que el pensamiento jurídico actual está dominado por teorías que no permiten saber si una decisión judicial determinada aplica o no un enunciado jurídico determinado, ni tampoco, por tanto, si un juez determinado cumple la segunda de sus obligaciones básicas.

En mi opinión, para que una decisión judicial aplique un enunciado jurídico determinado, es necesario que se cumplan ciertas condiciones, concretamente, tres. Aunque solo me referiré a dos de esas condiciones y a las teorías jurídicas que no permiten controlar el cumplimiento de esas dos condiciones.

Para exponer mis ideas, tomaré como ejemplo de enunciado jurídico el contenido en el art. 240.1 del CP español, que dice lo siguiente: «El culpable de robo con fuerza en las cosas será castigado con la pena de prisión de uno a tres años».

\subsection{Sobre los enunciados calificativos}

Una condición necesaria, en mi opinión, para que una decisión judicial aplique el enunciado jurídico que acaba de ser citado es que se haya cometido un robo con fuerza en las cosas, esto es, que haya ocurrido un caso comprendido bajo el supuesto de hecho de ese enunciado.

También se puede expresar esta misma idea usando la noción de enunciado calificativo. Un enunciado calificativo es un enunciado que es una concreción o instancia de sustitución del supuesto de hecho de un enunciado jurídico. Por ejemplo, el enunciado «Carlos es culpable de robo con fuerza en las cosas» es un enunciado calificativo, dado que es una concreción del supuesto de hecho de ese enunciado contenido en el art. 240.1 del CP español.

Podemos expresar la condición de la que estoy hablando de la manera siguiente: para que una decisión judicial aplique un determinado enunciado jurídico $E$, es necesario que sea verdadero un enunciado calificativo que sea una concreción del supuesto de hecho de $E$. De manera que, para que una decisión judicial aplique el enunciado contenido en el art. 240.1 del CP español, es necesario que sea verdadero un enunciado calificativo, como el enunciado «Carlos es culpable de robo con fuerza en las cosas», que sea una concreción del supuesto de hecho de dicho enunciado jurídico.

Y, conforme a la teoría semántica de la verdad elaborada por A. TARSKI e incorporada desde hace décadas a la metalógica, el que un enunciado calificativo, como el enunciado «Carlos es culpable de robo con fuerza en las cosas», sea verdadero o bien sea falso no depende de lo que diga un juez.

Estas ideas son rechazadas de una u otra manera por algunas teorías jurídicas actuales. A este respeto, podemos distinguir dos grupos de teorías: por un lado, las teorías conforme a las cuales nunca sería posible saber si un enunciado determinado es o 
no un enunciado calificativo verdadero; por otro lado, las teorías que hacen depender el que un enunciado calificativo sea verdadero de que lo que diga un juez.

Entre las primeras teorías mencionadas figuran ante todo aquellas que no permiten saber cuál es el supuesto de hecho de un enunciado jurídico. Obviamente, si no sabemos cuál es el supuesto de hecho de un enunciado jurídico $E$, tampoco podemos saber si un enunciado determinado es un enunciado calificativo, que es una concreción del supuesto de hecho de $E$. Las teorías a las que estoy aludiendo ahora son aquellas que afirman que los enunciados jurídicos, todos o algunos de ellos, son derrotables.

Según una definición ofrecida por C. E. AlCHOURRón, un enunciado condicional derrotable es un enunciado condicional que tiene excepciones implícitas ${ }^{12}$. Entendida de esta manera, la derrotabilidad de los enunciados jurídicos no plantea ninguna dificultad. No hay ningún inconveniente en aceptar que el enunciado jurídico penal español que he citado, que castiga al culpable de robo con fuerza en las cosas, es derrotable porque contiene implícitamente la excepción de que no concurra ninguna de las circunstancias que eximen de la responsabilidad penal.

Pero no es así como suele ser entendida actualmente la derrotabilidad de los enunciados jurídicos. Pues la tesis que está bastante extendida en trabajos de filosofía del Derecho es la de que los enunciados jurídicos son derrotables porque contienen excepciones implícitas que no pueden ser precisadas de una vez para siempre, puesto que esas excepciones varían de un caso a otro ${ }^{13}$. Esta tesis implica que no es posible saber en abstracto cuál es o qué significa el supuesto de hecho de un enunciado jurídico $E$, ni tampoco, por tanto, si un enunciado determinado es un enunciado calificativo, que es una concreción de dicho supuesto de hecho ${ }^{14}$.

Por ejemplo, a primera vista, diríamos que el enunciado «Carlos es culpable de robo con fuerza en las cosas» es una concreción del supuesto de hecho del enunciado jurídico contenido en el art. 240.1 del CP español. Sin embargo, en el caso de que ese enunciado fuera verdadero, pero Carlos hubiera robado, vamos a suponer, para dar lo robado a los pobres, algún partidario de la derrotabilidad de los enunciados jurídicos diría quizá que el supuesto de hecho del enunciado jurídico citado contiene implícitamente la excepción de que el producto del robo no sea para hacer obras de beneficencia; por lo cual el sentido de dicho enunciado jurídico sería el siguiente: «El culpable de robo con fuerza en las cosas, sin la finalidad de hacer obras de beneficencia, será castigado con la pena de prisión de uno a tres años». En consecuencia, este partidario de la derrotabilidad diría que el enunciado «Carlos es culpable de robo con fuerza en las cosas» es verdadero, pero no es un enunciado calificativo, porque no es una concreción del supuesto de hecho del art. 240.1 del CP español (ni de ningún otro enunciado jurídico). Este autor diría entonces que, en el caso que estamos considerando, un enunciado que es una concreción del supuesto de hecho de ese enunciado jurídico y, por tanto, un enunciado calificativo es el enunciado «Carlos es culpable de robo con fuerza

12 Alchourrón, 1996: 341.

13 Según BAYÓN, 2000: 91, una norma derrotable es «una norma sujeta a excepciones implícitas que no pueden ser enumeradas exhaustivamente de antemano, de manera que no sería posible precisar por anticipado las circunstancias que operarían como genuina condición suficiente de aplicación».

14 «Si una norma jurídica es realmente derrotable, entonces no es posible derivar de ella calificaciones normativas concluyentes para casos individuales» (BAYÓN, 2000: 113, nota 50). 
en las cosas, sin la finalidad de hacer obras de beneficencia». Pero, seguiría diciendo el mismo autor, este enunciado, aunque sería un enunciado calificativo, sería falso, dado que Carlos ha robado con la finalidad de hacer obras de beneficencia.

De manera que los partidarios de la derrotabilidad de los enunciados jurídicos introducen excepciones, vamos a decirlo así, en el supuesto de hecho de los enunciados jurídicos, en atención al caso litigioso de que se trate (normalmente por razones morales, aunque vengan disfrazadas de razones jurídicas, repletas de contenido moral) y que varían, por tanto, de un caso a otro. Y la consecuencia final es que, si esas teorías de la derrotabilidad fueran verdaderas, nunca sería posible saber en un litigio cualquiera si se da o no una condición que es, en mi opinión, necesaria para que una decisión judicial aplique un enunciado jurídico $E$ : la condición de que sea verdadero un enunciado calificativo que sea una concreción del supuesto de hecho de $E$.

Tampoco permiten saber si un enunciado determinado es o no un enunciado calificativo verdadero, o sea, si ha sucedido un caso comprendido bajo el supuesto de hecho de un enunciado jurídico, las teorías o autores que afirman que los enunciados calificativos, como «Carlos es culpable de robo con fuerza en las cosas», «Manuel es un homicida», «María ha causado un daño por negligencia», etc., son enunciados valorativos. Es difícil saber qué significa la afirmación de que los enunciados calificativos son enunciados valorativos. Pero me parece que esta afirmación implica que los enunciados calificativos no son verdaderos, ni falsos. Y su consecuencia es la siguiente:

Supongamos que una decisión judicial $D$ condena a Carlos, acusado de robo con fuerza en las cosas, a una pena de un año de prisión. En mi opinión, el que esa decisión $D$ aplique o no el art. 240.1 del CP español depende de que sea verdadero el enunciado calificativo «Carlos es culpable de robo con fuerza en las cosas». Pero si este enunciado no es verdadero, es decir, si no es verdad que Carlos es culpable de robo con fuerza en las cosas, no veo cómo se podría alcanzar la conclusión de que la decisión $D$ aplica dicho enunciado jurídico. Si el enunciado calificativo «Carlos es culpable de robo con fuerza en las cosas» no es verdadero, ni tampoco falso, quizá la conclusión tendría que ser que la decisión $D$ ni aplica, ni no aplica ese precepto penal.

El segundo grupo de teorías que he mencionado antes está integrado por aquellas que pueden aceptar que los enunciados calificativos son verdaderos o falsos, pero sostienen, de un modo u otro, que el que un enunciado calificativo sea verdadero o falso, el que haya ocurrido o no un caso comprendido bajo el supuesto de hecho de un enunciado jurídico, depende de lo que diga un juez.

A este respecto pueden ser citadas dos teorías, que ilustraré con el ejemplo del citado art. 240.1 del CP español («El culpable de robo con fuerza en las cosas será castigado con la pena de prisión de uno a tres años»).

Según una de esas teorías, el supuesto de hecho de este enunciado jurídico se refiere a los que roban. Pero el que un sujeto robe o no robe depende de que lo que diga un juez. Mientras un juez no se pronuncie al respecto, por ejemplo, durante la tramitación del procedimiento judicial en el que al acusado se le imputa un robo, el acusado solo es «presunto» autor del delito. Pero, una vez que el juez se pronuncia sobre esta cuestión, el acusado ya es indiscutiblemente o culpable del delito o inocente, según cual haya sido el pronunciamiento del juez. 
Otra de las teorías a las que aludo es la sostenida por H. KELSEN y tiene que ver con la interpretación, tema del que voy a hablar a continuación. KELSEN sostiene tesis según las cuales el supuesto de hecho de ese art. 240.1 del CP español no se refiere a los que roban, sino a los que un juez considera probado, conforme a las leyes procesales, que han robado ${ }^{15}$. Conforme a dichas tesis, un enunciado calificativo que sería una concreción del supuesto de hecho del art. 240.1 del CP español no sería el enunciado «Carlos es culpable de robo con fuerza en las cosas», sino el enunciado «Un juez considera probado, conforme a las leyes procesales, que Carlos es culpable de robo con fuerza en las cosas». Naturalmente, el que este enunciado sea un enunciado verdadero depende de que haya tenido lugar un determinado pronunciamiento judicial. Por tanto, si ese enunciado fuera un enunciado calificativo, como sostiene KELSEN, el que dicho enunciado calificativo fuera verdadero o falso, el que haya ocurrido o no un caso comprendido bajo el supuesto de hecho del citado art. 240.1 del CP español, dependería de lo que dijera un juez.

\subsection{Sobre la interpretación de los enunciados jurídicos}

Voy a referirme ahora a otro de los requisitos que es necesario, en mi opinión, para que una decisión judicial aplique un enunciado jurídico.

Llamo «enunciado interpretativo» a un enunciado que atribuye sentido a un determinado enunciado jurídico $E$ o que dice qué es lo que significa un determinado enunciado jurídico $E$.

Un ejemplo de enunciado interpretativo es el siguiente:

[3] El sentido del art. 240.1 del CP español es que los que cometan un robo con fuerza en las cosas serán castigados con la pena de uno a tres años de prisión.

Pero también es un enunciado interpretativo el siguiente enunciado:

[4] El art. 240.1 del CP español significa que los que cometan un robo con fuerza en las cosas serán castigados a cadena perpetua.

Mas, aunque ambos sean enunciados interpretativos, existe una diferencia evidente entre dichos enunciados: el primero de ellos es verdadero, mientras que el segundo es falso. Por ello, sostengo que los enunciados interpretativos son verdaderos o falsos, es decir, son enunciados asertivos; aunque frecuentemente tengamos dudas acerca de si un enunciado interpretativo determinado es verdadero o no. Y pienso también que el que un enunciado interpretativo sea verdadero o sea falso no depende de lo que diga un juez, al igual que ocurre en el caso de cualquier otro enunciado asertivo.

A mi juicio, para que una decisión judicial aplique un determinado enunciado jurídico $E$, es necesario que sea verdadero un determinado enunciado interpretativo acerca del sentido de $E$.

Por ejemplo, supongamos que el juez que juzga a Carlos, acusado de robo con fuerza en las cosas, dicta una decisión, llamémosla $\left\langle D_{1} »\right.$, que castiga a Carlos a una pena de dos años de prisión. Una de las condiciones necesarias para que esta decisión

15 Véase KelsEN, 1960: 245. 
aplique el enunciado jurídico contenido en el art. 240.1 del CP español es que sea verdadero el enunciado calificativo «Carlos es culpable de robo con fuerza en las cosas». Pero también es necesario que dicho enunciado jurídico signifique lo que significa, esto es, que sea verdadero el enunciado interpretativo [3]. Si el enunciado jurídico citado significara otra cosa, por ejemplo, si fuera verdadero el enunciado interpretativo [4], la decisión $« D_{1} »$ no aplicaría ese enunciado jurídico ${ }^{16}$.

Supongamos, en cambio, que la decisión dictada por el juez en el mismo litigio no fuera la decisión $\left\langle D_{1} »\right.$, sino una decisión $\left\langle D_{2} »\right.$, que castiga a Carlos a cadena perpetua. Esta decisión $« D_{2} »$ no aplicaría el enunciado contenido en el art. 240.1 del CP español, dado el sentido que este enunciado jurídico tiene. Pero sí lo aplicaría si el sentido de este enunciado jurídico fuera el que le atribuye el enunciado interpretativo [4], o sea, si este enunciado interpretativo [4] fuera verdadero.

Las ideas que acabo de exponer son opuestas a las que dominan en el pensamiento jurídico actual. Una idea muy difundida en la actualidad (a través especialmente de la denominada «escuela genovesa», liderada por R. GUASTINI) es que los enunciados interpretativos de los enunciados jurídicos no son verdaderos, ni falsos. Esta es una tesis general, refutada por los datos incuestionables de que el enunciado interpretativo [3] es verdadero, mientras que el enunciado interpretativo [4] es falso. Pero además, si el enunciado interpretativo [3] no fuera verdadero, y suponiendo que Carlos hubiera cometido un robo con fuerza en las cosas, no me imagino qué teoría de la aplicación de los enunciados jurídicos permitiría alcanzar la conclusión de que la decisión « $D_{1} »$ (que castiga a Carlos a una pena de dos años de prisión) aplica el art. 240.1 del CP español; del mismo modo, tampoco veo cómo sería posible concluir, en ese mismo caso del robo cometido por Carlos, que la decisión $\left\langle D_{2} »\right.$ (que castiga a Carlos a cadena perpetua) no aplica el mismo enunciado jurídico, si resulta que el enunciado interpretativo [4] no es falso. Esta teoría de la interpretación, que sostiene que los enunciados interpretativos no son verdaderos, ni falsos, también ha de ser incluida, por tanto, en esa lista de teorías que no permiten controlar la actividad judicial, concretamente, entre las que no permiten saber si una decisión judicial aplica o no un enunciado jurídico determinado.

Otra teoría de la interpretación que también hay que incluir en la lista citada es la que sostiene que la tarea de un intérprete de un enunciado jurídico $E$ no consiste, o no consiste solo, en formular un enunciado metalingüístico acerca del enunciado $E$, acerca del sentido E, como los enunciados [3] y [4]. Según la teoría a la que ahora aludo, muy difundida tácitamente en sentencias judiciales, la interpretación de un enunciado jurídico $E$ puede culminar con la formulación de un enunciado $X$, del mismo nivel lingüístico que $E$, referente al mismo asunto al que se refiere $E$, pero con un sentido

16 Para que la decisión $D_{1}$ aplique el art. 240.1 del CP español, son necesarios esos dos requisitos: que sea verdadero un determinado enunciado calificativo $F$, que sea una concreción del supuesto de hecho de dicho precepto, y que sea verdadero un enunciado interpretativo, que afirma que ese precepto significa (lo mismo que el enunciado) $I$. Pero, según he dicho antes, también es necesaria, en mi opinión, una tercera y última condición. Esta otra condición consiste en que ha de existir una determinada relación $R$ entre tres cosas, tres enunciados: el enunciado calificativo $F$ (que, al ser verdadero, describe lo que ha sucedido en el mundo), el enunciado $I$ (que expresa el sentido que tiene el precepto de cuya aplicación se trata) y la decisión $D_{1}$. Mas determinar en qué consiste esa relación $R$, que es el problema más complejo y polémico del tema de la aplicación de los enunciados jurídicos, es irrelevante en el presente contexto. 
distinto, quizá incluso opuesto, a lo que $E$ significa. Ese enunciado jurídico $X$ es presentado por la teoría de la interpretación de la que estoy hablando como un enunciado o norma que es producto de la interpretación, concretamente, como producto de una interpretación calificada como «correctiva».

Aunque cuando ese enunciado $X$ es formulado por un Tribunal en una sentencia, en particular por el Tribunal Supremo, puede ocurrir que dicho enunciado no sea presentado como producto de una labor interpretativa. Puede suceder que el citado enunciado $X$ sea presentado como «doctrina jurisprudencial», rótulo que cubre el resultado de esa actividad que a veces realiza el Tribunal Supremo y que consiste en crear normas o enunciados de carácter general.

Voy a citar a continuación un par de ejemplos de esas doctrinas jurisprudenciales del Tribunal Supremo español.

Una de ellas, bien conocida por los civilistas españoles, es la que dice que las obligaciones pueden ser solidarias, aunque no se pacte así expresamente ${ }^{17}$; justamente lo contrario de lo que dice el art. 1.137 del CC español ${ }^{18}$.

Pero más llamativo es este otro ejemplo. El art. 18.1 de la Constitución Española dice lo siguiente: «Se garantiza el derecho al honor, a la intimidad personal y familiar y a la propia imagen».

Por otra parte, el texto literal del art. 20 de la Constitución Española es el siguiente:

1. Se reconocen y protegen los derechos:

a) A expresar y difundir libremente los pensamientos, ideas y opiniones mediante la palabra, el escrito o cualquier otro medio de reproducción.

b) A la producción y creación literaria, artística, científica y técnica.

c) A la libertad de cátedra.

d) A comunicar o recibir libremente información veraz por cualquier medio de difusión. La ley regulará el derecho a la cláusula de conciencia y al secreto profesional en el ejercicio de estas libertades.

2. El ejercicio de estos derechos no puede restringirse mediante ningún tipo de censura previa.

3. La ley regulará la organización y el control parlamentario de los medios de comunicación social dependientes del Estado o de cualquier ente público y garantizará el acceso a dichos medios de los grupos sociales y políticos significativos, respetando el pluralismo de la sociedad y de las diversas lenguas de España.

4. Estas libertades tienen su límite en el respeto a los derechos reconocidos en este Título, en los preceptos de las leyes que lo desarrollen y, especialmente, en el derecho al honor, a la intimidad, a la propia imagen y a la protección de la juventud y de la infancia [cursiva añadida].

5. Sólo podrá acordarse el secuestro de publicaciones, grabaciones y otros medios de información en virtud de resolución judicial.

17 STS, de la Sala de lo Civil, 239/1998, de 18 de marzo, FJ 8. $:$ :Si la mancomunidad se pacta expresamente para unas, y para las otras no se dice nada, es que aquéllas se excepcionan del régimen de la solidaridad que se pretende como situación normal».

${ }_{18}$ El texto de este artículo es el siguiente: «La concurrencia de dos o más acreedores o de dos o más deudores en una sola obligación no implica que cada uno de aquéllos tenga derecho a pedir, ni cada uno de estos deba prestar íntegramente, las cosas objeto de la misma. Solo habrá lugar a esto cuando la obligación expresamente lo determine, constituyéndose con el carácter de solidaria». 
Con relación a estos textos constitucionales, el Tribunal Supremo ha formulado enunciados que dicen justamente lo contrario de lo que dice la Constitución Española: que es el derecho al honor el que está limitado por la libertad de expresión e información. La STS, de la Sala 1. ${ }^{a}, 234 / 2013$, de 25 de marzo, FJ 3. ${ }^{\circ}$, dice lo siguiente: «El derecho al honor, según reiterada jurisprudencia, se encuentra limitado por las libertades de expresión e información». Y lo mismo se observa en la STS, de la misma Sala 1. ${ }^{a}, 149 / 2015$, de 17 de marzo, FJ 2. ${ }^{\circ}$ : «La limitación del derecho al honor por la libertad de expresión e información tiene lugar cuando se produce un conflicto entre ambos derechos».

Respecto a esos enunciados generales formulados por el Tribunal Supremo, ya sean considerados productos de la interpretación, ya sean calificados como «doctrina jurisprudencial», hay que tener en cuenta: a) que cuando en un litigio un tribunal formula un enunciado general $X$ en sustitución, por así decirlo, de un enunciado jurídico $E$ previo, formulado por el legislador, el enunciado aplicado por la decisión dictada por el tribunal será $X$, el enunciado nuevo creado por el tribunal, no el enunciado $E$ anterior $^{19}, \mathrm{y} b$ ) según las tesis que he expuesto y justificado en el apartado $\mathrm{V}$, esta aplicación del nuevo enunciado $X$ no debería contar como aplicación del Derecho, aunque consideremos que $X$ es un enunciado jurídico.

Al comienzo de este trabajo, he dicho que es importante controlar a nivel teórico si en un caso determinado un juez determinado cumple o no las obligaciones que el Derecho le impone. Pero si lo que un juez está obligado a hacer en un caso determinado dependiera de la concurrencia de alguna circunstancia (por ejemplo, de la existencia o no de una norma, principio, etc.), que a su vez dependiera de una determinada conducta del juez (por ejemplo, de su actividad interpretativa, o de su doctrina jurisprudencial), respecto a la cual no existen criterios de control, la consecuencia inmediata sería la inexistencia de criterios teóricos que permitan controlar si en un caso determinado un juez determinado cumple o no las obligaciones que el Derecho le impone. Y la consecuencia final no sería la arbitrariedad, denunciada por MONTESQUIEU en los casos en los que, como los que ahora nos ocupan, el titular de la potestad judicial ejerce además la potestad legislativa ocasionalmente ${ }^{20}$. Sería algo más grave que eso. Pues la arbitrariedad es la conducta ilegal de los poderes públicos ${ }^{21}$; por lo cual una conducta arbitraria es una conducta contraria a una regla (legal), que funciona como criterio de control de las conductas y sirve para reprobar las conductas que se apartan de ella. Pero si de lo que se trata es que no existen criterios que permitan controlar la conducta de un juez, ni siquiera existe la posibilidad de reprobar dicha conducta.

$\mathrm{Al}$ margen de estas observaciones, me parecen equivocadas las teorías que aceptan esos enunciados generales formulados por el Tribunal Supremo, y que antes han sido citados, tanto si dichos enunciados son considerados productos de una interpretación correctiva del Derecho, como si son calificados como doctrina jurisprudencial.

19 Según SCHAUER, 2013: 126-127, «es característico del common law que las reglas sean cambiadas en el mero proceso de su aplicación». Pero esta es una descripción engañosa de lo que sucede en los sistemas del common law y de lo que sucede en nuestro Derecho. Pues la regla que es cambiada, esto es, que es sustituida por otra, no es la regla aplicada; la aplicada es la otra, la nueva regla creada por el juez.

20 Véase MONTESQuieu, 1922: 152.

21 «"Arbitrario" equivale a no adecuado a la legalidad», dice la STC 27/1981, FJ 10. ${ }^{\circ}$ 
Pues, por un lado, es imposible que un intérprete corrija lo que constituye su objeto de interpretación, a no ser que abandone su condición de intérprete. La tarea consistente en corregir un enunciado jurídico y sustituirlo por otro enunciado distinto y tal vez opuesto al primero es una tarea legislativa, que queda fuera de las competencias del intérprete del Derecho. En cualquier caso, quienquiera que realice esa actividad correctora, esta no consiste en atribuir sentido o significado a una expresión; e interpretar es precisamente eso, atribuir sentido o significado a una expresión. Si, a pesar de todo, se insistiera en que eso es interpretar, habría que decir que se trata de interpretaciones falsas; pues, por ejemplo, los textos constitucionales citados significan justamente lo contrario de lo que el Tribunal Supremo afirma que significan o desea que signifiquen. No sé si un dictamen pericial, emitido por el director de la Real Academia Española, bastaría para convencer al Tribunal Supremo a este respecto.

Pero el problema reside precisamente en que nuestros altos Tribunales, así como los juristas teóricos, raramente hablan de textos, enunciados, constitucionales, y de su sentido o significado, sino de los principios, derechos, libertades, valores, etc., «consagrados» o «reconocidos» en los enunciados constitucionales correspondientes. Pues estos juristas contemplan la Constitución, no como un documento integrado por enunciados, por entidades lingüisticas, a semejanza del reglamento hipotecario, sino como un conjunto, calificado a veces como sistema, cuyos elementos o miembros son valores, principios, derechos, etc. Y los enunciados constitucionales son, para dichos juristas, una mera manifestación material de aquellas entidades inmateriales. Mas explicar esta relación de manifestación, reconocimiento o consagración de un principio, un derecho o un valor en un enunciado constitucional es un problema añadido a los señalados en páginas anteriores respecto a los principios: ante todo, el problema ontológico y el epistemológico; pero también el de cómo hacer compatible esa ontología con la tesis de la jerarquía normativa y con la teoría acerca de las relaciones entre Derecho y tiempo.

En cuanto a la posibilidad, en segundo lugar, de considerar esos enunciados generales formulados por el Tribunal Supremo como doctrina jurisprudencial, es una cuestión menor la de si esos enunciados generales son jurídicos (y los jueces crean Derecho) o no lo son, y si, en el primer caso, el Derecho creado por el Tribunal Supremo es un Derecho de segunda categoría. Lo importante es que los jueces y Tribunales, incluido el propio Tribunal Supremo, deciden los casos litigiosos como si dichos enunciados generales fueran Derecho, no solo de primera categoría, al lado de la ley, sino incluso con una categoría superior a la de esta. Y ello me parece erróneo por las razones siguientes:

Al crear doctrina jurisprudencial, el Tribunal Supremo infringe numerosos preceptos de la Constitución Española. Infringe, en primer lugar, sus arts. 117.3 y 117.4, que antes han sido citados, y según los cuales la única función de los jueces y Tribunales es la jurisdiccional, que consiste esencialmente en aplicar el Derecho creado por otras instancias. La doctrina jurisprudencial del Tribunal Supremo atenta también contra la democracia como forma de gobierno, consagrada en el art. 1.1 de la Constitución, dado que un Tribunal Judicial carece de representatividad política para crear normas generales; y cuando esas normas generales creadas por el Tribunal Supremo son, como 
en los casos citados, contrarias a lo que de modo inequívoco establecen normas generales contenidas en una ley o en la Constitución, y creadas por quienes sí ostentan la representación de los ciudadanos, entramos ya en lo antidemocrático. La doctrina jurisprudencial del Tribunal Supremo viola también en varios aspectos el art. 9.3 de la Constitución, que «garantiza» la seguridad jurídica, así como la irretroactividad y la publicidad de las normas. A todo ello hay que añadir los repentinos e imprevisibles «cambios de jurisprudencia», además de los abusos frecuentes a que esa práctica judicial da lugar, como revelan los ejemplos antes citados.

Resulta sorprendente, en mi opinión, que el Tribunal Supremo, capaz de detectar la más leve infracción de la Constitución, no atisbe el menor indicio de inconstitucionalidad en su propia práctica de crear doctrina jurisprudencial, a pesar de que los indicios que existen de ello son numerosos y evidentes. Pero me sorprende más aún la naturalidad con la que la cultura jurídica acepta esa práctica judicial, la pasividad del pensamiento jurídico ante una práctica que atenta contra muchas cosas que los juristas, en particular, y los ciudadanos, en general, estimamos valiosas y que, por ello, la Constitución intenta proteger.

\section{EPÍLOGO}

Cualquiera de las numerosas teorías que he expuesto y comentado es suficiente para impedir que algunos aspectos esenciales de la actividad judicial sean controlados. Pero el pensamiento jurídico actual acerca de la labor de los jueces es precisamente una mezcolanza de todas esas teorías. Y la consecuencia de esta mescolanza de teorías es que los jueces ejerzan su profesión bajo un descontrol teórico absoluto. La pasividad del pensamiento jurídico ante prácticas judiciales claramente antijurídicas halla su explicación precisamente en la inexistencia de criterios teóricos que permitan enjuiciar el trabajo de los jueces o bien en el hecho, más grave, de que los criterios teóricos que existen justifican dichas prácticas.

\section{BIBLIOGRAFÍA}

Alchourrón, C. E., 1996: «On Law and Logic», Ratio Iuris, 9 (4): 331-348.

ALEXY, R., 2003: «Die logische Analyse juristischer Entscheidungen», en R. ALEXY, H.-J. KocH,

L. Kuhlen y H. Russmann, Elemente einer juristischen Begründungslehre, Baden-Baden: Nomos, 9-35.

BAYÓN, J. C., 2000: «Derrotabilidad, indeterminación del Derecho y positivismo jurídico», Isonomía, 13: 87-117.

Guastini, R., 1996: «Fragments of a Theory of Legal Sources», Ratio Iuris, 9 (4): 364-386.

HERNÁNDEZ GIL, A., 1975: El Abogado y el Razonamiento jurídico, Madrid.

KeLsEn, H., 1960: Reine Rechtslebre. Mit einem Anbang: Das Problem der Gerechtigkeit, Wien:

Franz Deuticke.

Montesquieu, 1922: De l'esprit des lois, avec de notes de Voltaire, de Crevier, de Mably, de la Harpe, etc., tome premier, Paris: Librairie Garnier Frères.

NiETO, A., 2000: El arbitrio judicial, Barcelona: Ariel. 
Rousseau, J. J., 1979: «El Contrato Social o Principios de Derecho Político», en J. J. Rousseau, Escritos de combate, traducción y notas de S. MASÓ, Introducción, Cronología y Bibliografía de G. BENREKASSA, Madrid: Ediciones Alfaguara, 393-526.

SCHAUER, F., 2013: Pensar como un abogado. Una nueva introducción al razonamiento jurídico, traducción al castellano de T. J. SCHLEIDER, Madrid-Barcelona-Buenos Aires-São Paulo: Marcial Pons.

VRANAS, P. B. M., 2016: «New foundations for imperative logic III: A general definition of argument validity», Synthese, 193, 1703-1753. 